\title{
Air classification of blast furnace dust catcher dust for zinc load reduction at the sinter plant
}

\author{
C. Lanzerstorfer ${ }^{1}$
}

Received: 29 May 2015/Revised: 27 September 2015/Accepted: 7 October 2015/Published online: 19 October 2015

(C) Islamic Azad University (IAU) 2015

\begin{abstract}
The off-gas discharged from a blast furnace is de-dusted in a first stage by a dust catcher or a cyclone. The separated dust consists mainly of iron and coke. Therefore, most of this dust is recycled in the sinter plant. A higher $\mathrm{Zn}$ content of the dust is undesirable because the allowed $\mathrm{Zn}$ content in the sinter feed material is limited. The reduction of the $\mathrm{Zn}$ content of the dust by a simple process would be helpful in the case of higher $\mathrm{Zn}$ content in the blast furnace dust. In classification experiments, it has been demonstrated that the $\mathrm{Zn}$ content of the blast furnace dust increases with decreasing particle size. Thus, air classification of the dust can be applied to separate the Zn-enriched fines. By separating a small fraction of fines (about 10-20\%) from the blast furnace dust, a reduction of the mass of $\mathrm{Zn}$ in the remaining coarse fraction for recycling in the range of $40-60 \%$ is possible and only $5-10 \%$ of the carbon is lost.
\end{abstract}

Keywords Recycling - Dust treatment - Zinc separation · Blast furnace residues

\section{Introduction}

The blast furnace (BF) process is the most important process in integrated steel mills for the production of hot metal (pig iron). There the iron ore is reduced to metallic iron. The off-gas discharged from the BF, the so-called top-gas,

C. Lanzerstorfer

christof.lanzerstorfer@fh-wels.at

1 School of Engineering/Environmental Sciences, University of Applied Sciences Upper Austria, Stelzhamerstraße 23, 4600 Wels, Austria is de-dusted in a first stage by the dust catcher which separates the coarser dust form the top-gas (Lajtonyi 2006; Winfield et al. 2012). Alternatively, cyclones are used in some plants for the first off-gas cleaning step (Craig 2008; Suvorov 2009; Winfield et al. 2013). The final de-dusting is usually achieved in a subsequent scrubber (Streit 2007). In some BFs, especially in Japan and China, fabric filters are used for the second de-dusting stage (Murai et al. 1986; Zhang 2009; Lanzerstorfer and Xu 2014).

For European BFs, the average amount of dust separated in the dust catcher is $18 \mathrm{~kg}$ dust per ton of hot metal produced (Remus et al. 2013). The dust collected in the dust catcher consists mainly of iron oxides $(15-40 \% \mathrm{Fe})$ and coke particles $(25-40 \% \mathrm{C})$ which are fine enough to be carried by the discharged gas (Remus et al. 2013). Minor constituents are calcium oxide, aluminium oxide and silica (Das et al. 2007; Remus et al. 2013; Großpietsch et al. 2001). Therefore, the BF dust is usually recycled to the sinter plant (Hansmann et al. 2008; Skroch and MayerSchwinning 2012; Więcek and Mróz 2014) to recycle the valuable components.

However, there is also some zinc in the dust catcher dust. The $\mathrm{Zn}$ content is typically in the range of $0.1-0.5 \%$ (Remus et al. 2013). Zinc is an unwanted component in the sinter because it causes operational problems in the subsequent BF. It can form crusts in the upper part of the furnace and accumulates in the lining of the furnace which consequently deteriorates (Stepin et al. 2001; Koros 2003; Malemud et al. 2013; Doronin and Svyazhin 2011). Therefore, the total amount of zinc in the charge of a BF is usually restricted to $100-150 \mathrm{~g} / \mathrm{t}$ of hot metal produced (Remus et al. 2013). The zinc in the charge of the BF is mainly contained in the sinter (Stepin et al. 2001).

The sources of zinc in the sinter are usually recycling materials. In particular, dusts from the de-dusting of the BF 
and the basic oxygen furnace (BOF) off-gas contain zinc. The sinter plant is not very efficient in removing zinc from the feed material (Lanzerstorfer et al. 2015). Therefore, the zinc content in the feed material into the sinter plant has to be limited according to plant-specific conditions. Processes which reduce the content of zinc in the recycled dust can help to increase the admissible amount of recycled dust.

Asadi Zeydabadi et al. (1997) investigated the leaching of $\mathrm{Zn}$ from BF dust using sulphuric acid. Depending on the acid concentration, up to $80 \%$ of the $\mathrm{Zn}$ was removed from the dust, while at the same time only about $6 \%$ of the iron was dissolved. However, the drawback of leaching processes is the generation of a liquid effluent which has to be treated.

Jansson and Sundqvist Ökvist (2004) split BF dust by sieving it into six size fractions. The finest fraction was $<45 \mu \mathrm{m}$, while the coarsest fraction was $>250 \mu \mathrm{m}$. It was found that the iron content decreases from the finest fraction to the coarsest fraction, while the behaviour of the carbon content is the opposite. The $\mathrm{Zn}$ content in the dust fractions was quite constant. The range was $0.16-0.24 \%$. Only in the coarsest fraction, the $\mathrm{Zn}$ content was less $(0.09 \%)$.
When a component is enriched in the fine fraction of a dust, classification can be applied to split the dust into two size fractions with a different content of this component. This has been shown, for example, for the dry residue from sinter plant off-gas cleaning (Lanzerstorfer and Neuhold 2015). Air classification was also used to treat the dust collected in a second-stage fabric filter to separate a fine fraction with increased $\mathrm{Zn}$ content (Murai et al. 1986; Lanzerstorfer and Kröppl 2014). However, there is no information available regarding the use of air classification for the treatment of dust catcher dust.

The aim of this study was to investigate the application of air classification to reduce the amount of zinc fed to the sinter plant by BF dust recycling (Fig. 1). By air classification, the BF dust would be separated into a coarse fraction with a reduced $\mathrm{Zn}$ content and a fine fraction with an increased $\mathrm{Zn}$ content. In such a classification, an important parameter to be investigated is the cut size in dependence of the efficiency of the Zn separation. The Znenriched fines fraction can be fed to a $\mathrm{Zn}$ leaching process or to the BOF. Dust from the dust catcher of the top-gas dedusting of an industrial BF was separated into several size fractions by air classification. From the results of the
Fig. 1 Flow sheet for BF dust recycling applying classification recycling applying classification

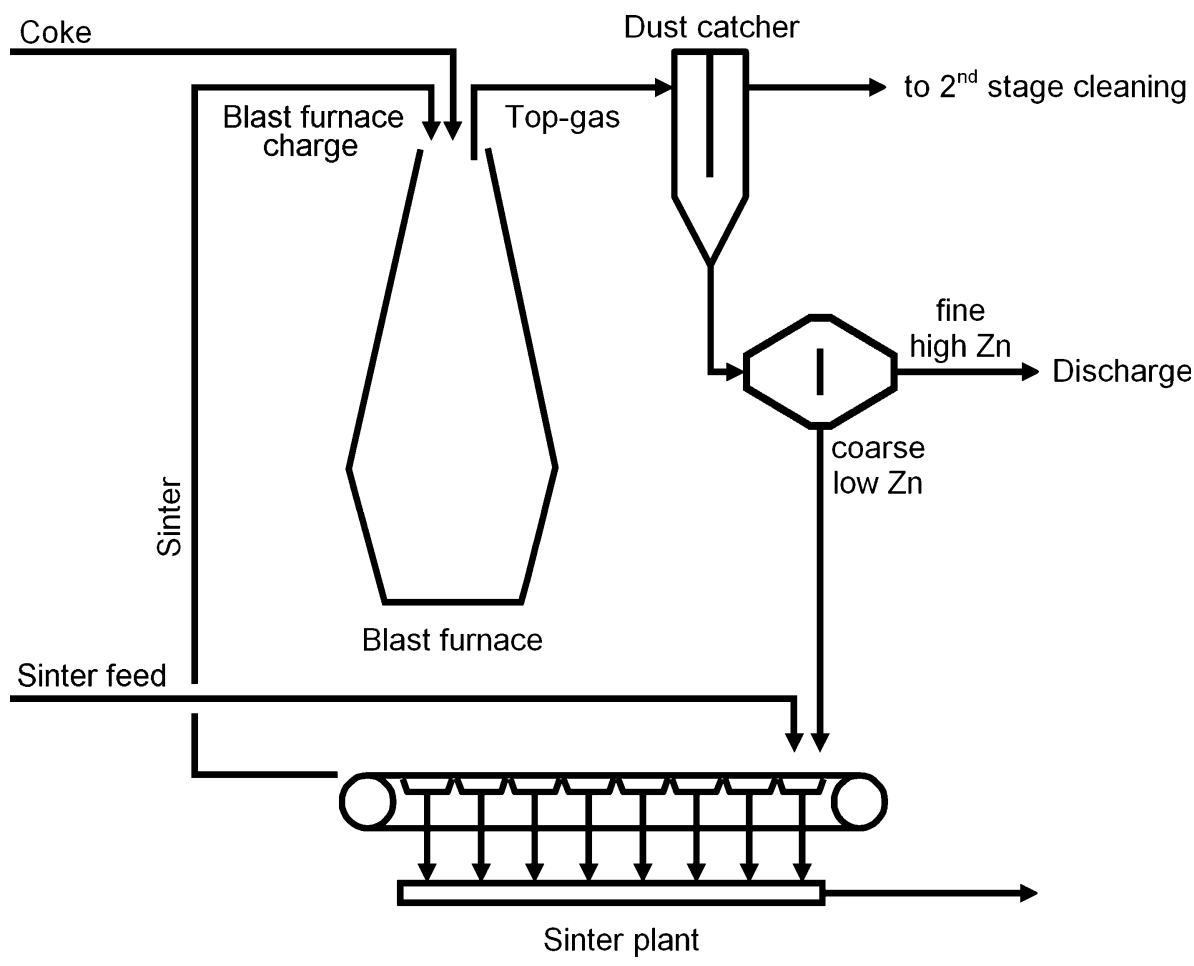


chemical analysis of the size fractions, the elimination efficiency of the classification process for zinc at various recycling rates was calculated.

The work was carried out in spring 2015 at the University of Applied Sciences Upper Austria, Wels Campus.

\section{Materials and methods}

\section{Dust sample classification}

The dust sample investigated was collected from the dust catcher of the top-gas cleaning system of an industrial BF. Approximately $2 \mathrm{dm}^{3}$ of dust was taken from the dust discharge. For dry classification, a laboratory classifier 100 MZR from Hosokawa Alpine was used. The classification procedure is described in detail elsewhere (Lanzerstorfer and Kröppl 2014). The speed of the classifier in the four classification runs was $21,000,11,000$, 6,000 and $3,000 \mathrm{rpm}$. Thus, the dust was split into five sized fractions.

\section{Sample analysis}

The volume of the classified samples was reduced to a volume suitable for the analysis using a Quantachrome Micro Riffler sample divider. The moisture content of the dust samples was measured gravimetrically using a MA35M infrared moisture analyser from Sartorius. The particle size distribution of the dust samples was measured using a HELOS/RODOS laser diffraction instru- ment with dry sample dispersion from Sympatec. The samples were digested in concentrated boiling $\mathrm{HCl}$ for $2 \mathrm{~h}$. The digestion procedure was similar to that used by Leclerc et al. (2003); only the digestion time was longer. After dissolving samples, the concentration of $\mathrm{Zn}$ was determined by flame atomic absorption spectrometry. The concentration of Fe was determined in the dissolved samples after reduction of $\mathrm{Fe}^{3+}$ with $\mathrm{Sn}(\mathrm{II})$-chloride by potentiometric titration according to Zimmermann-Reinhardt. The total carbon (TC) content of the dust catcher dusts was determined using a LiquiTOC system with a Solids Material extension from Elementar Analysensysteme.

\section{Results and discussion}

\section{Characterization of the dust catcher dust}

The moisture content of the dust was $1.2 \%$, the Fe content was $39.4 \%$, and the TC content was $28.2 \%$. Compared to the literature data for $\mathrm{BF}$ dust, the investigated dust is relatively high in $\mathrm{Fe}$ content and low in TC content (Remus et al. 2013). The $\mathrm{Zn}$ content of the dust was $0.52 \%$. Thus, the $\mathrm{Zn}$ content is at the upper limit of the range described in the literature (Remus et al. 2013). The mass median diameter of the dust was $130 \mu \mathrm{m}$.

\section{Classified dust catcher dust}

The cut size of the first, second, third and fourth classification runs was $2.1,4.5,9.2$ and $32 \mu \mathrm{m}$, respectively. The
Table 1 Particle classes produced from the BF dust sample

\begin{tabular}{lccllll}
\hline & Mass fraction in $\%$ & $\mathrm{x}_{10}$ in $\mu \mathrm{m}^{\mathrm{a}}$ & $\mathrm{x}_{90}$ in $\mu \mathrm{m}^{\mathrm{a}}$ & $\mathrm{Fe}$ in $\mathrm{g} / \mathrm{kg}$ & $\mathrm{Zn}$ in g/kg & $\mathrm{TC}$ in g/kg \\
\hline Particle class 1 & 4.3 & 0.54 & 3.75 & 234 & 36.0 & 138 \\
Particle class 2 & 5.1 & 2.29 & 8.64 & 329 & 15.2 & 132 \\
Particle class 3 & 6.9 & 3.49 & 17.4 & 375 & 9.93 & 133 \\
Particle class 4 & 15.8 & 10.4 & 36.4 & 444 & 4.63 & 150 \\
Particle class 5 & 67.9 & 29.2 & 214 & 393 & 2.07 & 349 \\
\hline
\end{tabular}

${ }^{\mathrm{a}} \mathrm{x}_{10}$ is the particle size with $10 \%$ of the mass of the material consisting of particles smaller than this size and the remaining mass of the material consisting of larger particles. $x_{90}$ is defined in a similar way 


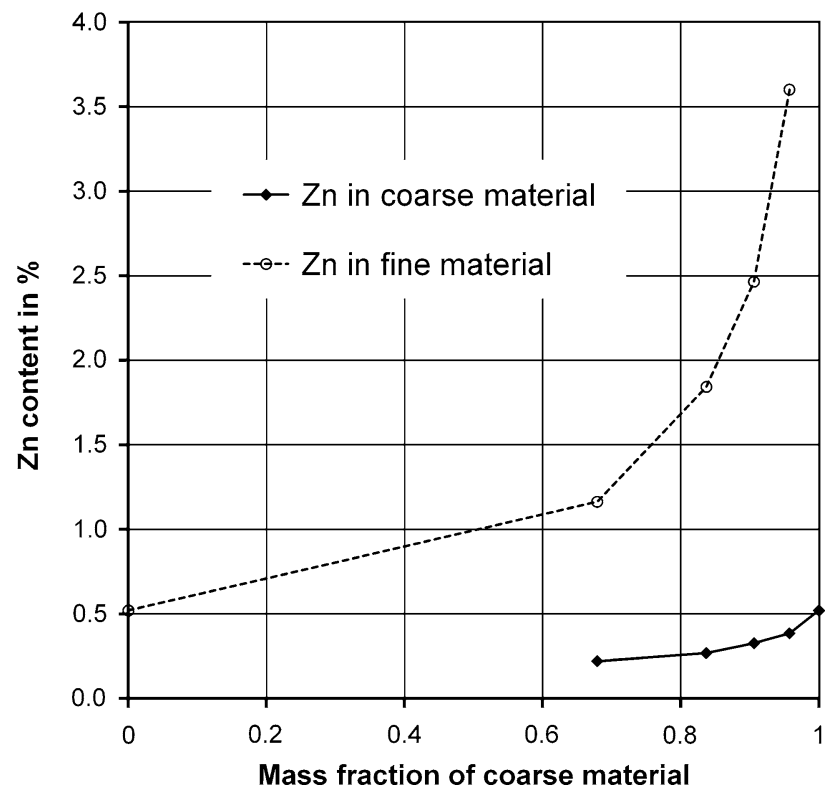

Fig. $2 \mathrm{Zn}$ content in the coarse material and in the fine material as a function of the coarse material fraction

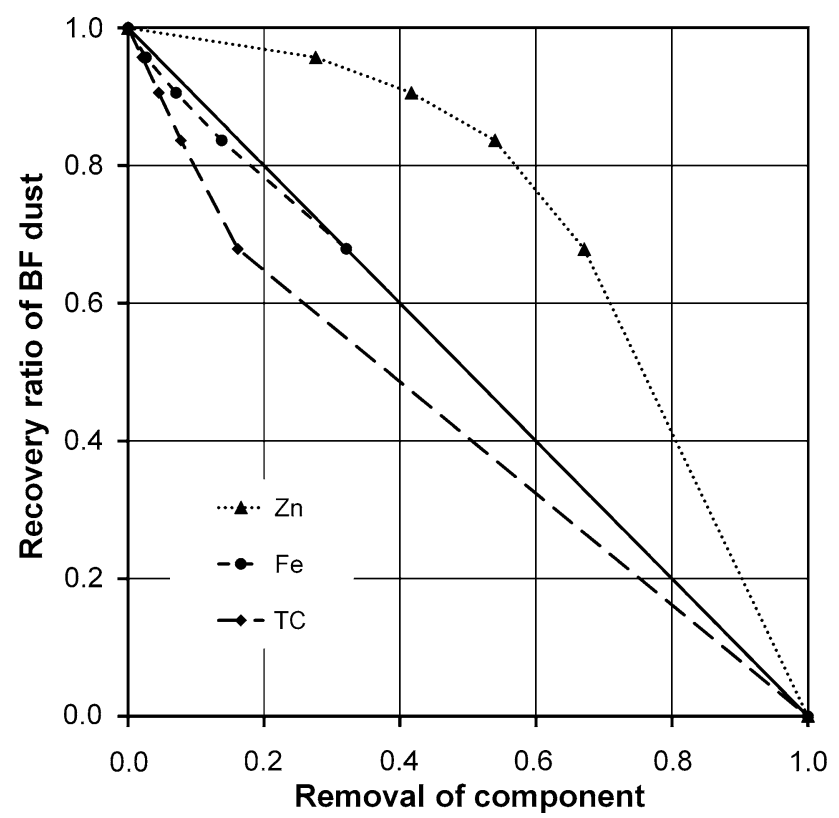

Fig. 3 Recovery ratio of BF dust as a function of the removal of various components mass fractions of the five $\mathrm{BF}$ dust particle classes produced and their size ranges are summarized in Table 1. The content of $\mathrm{Zn}, \mathrm{Fe}$ and $\mathrm{TC}$ in the various particle classes is also shown in Table 1.

$\mathrm{Fe}$ is the main component in the BF dust. From particle class 1 to particle class 4 , the $\mathrm{Fe}$ content increases with increasing particle size, whereas in the coarsest particle class the $\mathrm{Fe}$ content is lower. The $\mathrm{Zn}$ content is highest in the finest particle class and is approximately halved from particle class to particle class. For the finer particle classes, the carbon content is constantly low, while in the coarsest particle class it is more than twice as high.

The $\mathrm{Zn}$ content calculated for the coarse material and the fine material as a function of the coarse material mass fraction is shown in Fig. 2. The terms coarse material and fine material refer to the two fractions of material obtained by classification of the BF dust in a process with similar separation characteristics as the air classifier used in the experiment. The calculations required to obtain such a diagram from the classification experiments are described elsewhere (Lanzerstorfer 2015). When only the finest material is separated by classification, the mass fraction of the remaining amount of coarse material for recycling is only reduced slightly. The reduction of the $\mathrm{Zn}$ content in the coarse material is considerable, and the $\mathrm{Zn}$ content in the fine fraction is high. With decreasing coarse mass fraction, the $\mathrm{Zn}$ content decreases continuously, for both the remaining coarse fraction and the fine fraction.

\section{Recycling of classified BF dust}

The mass flow rate of $\mathrm{Zn}$ to the sinter plant caused by the recycling of air classified $\mathrm{BF}$ dust is a function of the mass fraction of the coarse material as well as the $\mathrm{Zn}$ content of the coarse fraction. In Fig. 3 this connection is shown. For instance, about $40 \%$ of the $\mathrm{Zn}$ can be removed with the finest $10 \%$ of the BF dust separated by air classification. The removal rate for $\mathrm{Fe}$ and $\mathrm{TC}$ is below the removal rate for the total mass of the BF dust because these components are depleted in the fine fractions. The calculated curve is therefore below the neutral line connecting the points $(1 / 0)$ and $(0 / 1)$. 
The results show that air classification would be an effective method to reduce the recycling of $\mathrm{Zn}$ to the sinter plant. The coarse fraction is depleted in $\mathrm{Zn}$ and enriched in TC, while the Fe concentration is nearly unchanged. A small fraction of fines has to be discharged. As the $\mathrm{Zn}$ content is still relatively low (2-3\%), recycling via the BOF could be considered.

\section{Conclusion}

Recycling of the BF dust separated in the dust catcher or cyclone to the sinter plant is the state of the art for the utilization of this residue. However, an increased $\mathrm{Zn}$ content of the recycled dust is undesirable because of the plantspecific limits for the $\mathrm{Zn}$ content in the sinter feed material. Therefore, processes which reduce the $\mathrm{Zn}$ content of the recycled material can help to increase the recycling rates, especially in the case of a higher $\mathrm{Zn}$ content of the dust. In the experiments, it has been demonstrated that air classification would be an effective method for the treatment of BF dust. By separating a small fraction of fines (about 10-20\%) from the BF dust, a reduction of the mass of $\mathrm{Zn}$ in the coarse dust recycled to the sinter plant in the range of $40-60 \%$ is possible. The loss of TC would be only approximately $5-10 \%$.

Acknowledgments The author wants to thank the University of Applied Sciences Upper Austria for funding the work (KSt 8541). Fe and $\mathrm{Zn}$ analysis by G.-C. Kastner and proofreading by D. Moser are gratefully acknowledged.

\section{References}

Asadi Zeydabadi B, Mowla D, Shariat MH, Fathi Kalajahi J (1997) Zinc recovery from blast furnace dust. Hydrometallurgy 47(1):113-125

Craig IM (2008) Innovative technologies for blast furnaces. Stahl Eisen 128(11):S89-S97

Das B, Prakash S, Reddy PSR, Misra VN (2007) An overview of utilization of slag and sludge from steel industries. Resour Conserv Recycl 50(1):40-57

Doronin IE, Svyazhin AG (2011) Commercial methods of recycling dust from steelmaking. Metallurgist 54(9-10):673-681

Großpietsch K-H, Lüngen HB, Theobald W (2001) BAT an Hochöfen-eine Bestandsaufnahme zum derzeitigen Umweltschutz an Hochöfen. Stahl Eisen 121(5):51-57
Hansmann T, Fontana P, Chiappero A, Both I, Roth J-L (2008) Technologies for the optimum recycling of steelmaking residues. Stahl Eisen 128(5):29-35

Jansson B, Sundqvist Ökvist L (2004) Injection of BF flue dust into the BF-a full-scale test at BF No. 3 in Luleå. In: SCANMET II, 2nd international conference on process development in iron and steelmaking, June 6-9, 2004, Luleå

Koros PJ (2003) Dusts, scale, slags, sludges ... not wastes, but source of profits. Metall Mater Trans B 34B:769-779

Lajtonyi A (2006) Blast furnaces gas cleaning systems. Millenium Steel 2006:57-65

Lanzerstorfer C (2015) Air classification-a potential treatment method of fine grained residues collected in dry off-gas cleaning systems of high temperature processes for optimized dust recycling or utilization. Waste Manage Res. doi:10.1177/ $0734242 X 15597997$

Lanzerstorfer C, Kröppl M (2014) Air classification of blast furnace dust collected in a fabric filter for recycling to the sinter process. Resour Conserv Recycl 86:132-137

Lanzerstorfer C, Neuhold R (2015) Residues from single-stage dry de-dusting and desulphurization of sinter plant off-gas: enabling partial recirculation by classification. Intern $\mathrm{J}$ Environ Sci Technol 12:2939-2946

Lanzerstorfer C, Xu Q (2014) Neue Entwicklungen zur Gichtgasreinigung von Hochöfen: ein Überblick. BHM 159:91-98

Lanzerstorfer C, Bamberger-Straßmayr B, Pilz K (2015) Recycling of blast furnace dust in the iron ore sinter process: investigation of coke breeze substitution and the influence on off-gas emissions. ISIJ Int 55(4):758-764

Leclerc N, Meux E, Lecuire J-M (2003) Hydrometallurgical extraction of zinc from zinc ferrites. Hydrometallurgy 70:175-183

Malemud SG, Mal'tsev VA, Yurév BP (2013) Kinetic analysis of the reduction of zinc and iron oxides from dust and slurry. Steel Transl 43:78-82

Murai T, Kometani A, Ono Y, Hashimoto T (1986) Blast furnace gas dry cleaning system and dry removal system of zing in dry dust. Sumitomo Search 32:1-7

Remus R, Aguado-Monsonet MA, Roudier S, Sancho LD (2013) Best available techniques (BAT) reference document for iron and steel production, industrial emissions directive 2010/75/EU, integrated pollution prevention and control. Publications Office of the European Union, Luxembourg

Skroch R, Mayer-Schwinning G (2012) Iron, 6. Aspects of environmental protection. In: Ullmann's encyclopedia of industrial chemistry, vol 20. Wiley-VCH, Weinheim, pp 25-31

Stepin GM, Mkrtchan LS, Dovlyadnov IV, Borshchevskii IK (2001) Problems related to the presence of zinc in Russian blast-furnace smelting and ways of solving them. Metallurgist 45(9-10):382-390

Streit GT (2007) Gas cleaning systems in ironmaking blast furnaces. In: Proceedings of ASITech 2007, Indianapolis, 2007. Association for Iron \& Steel Technology, Warrendale, pp 1-8

Suvorov MN (2009) Equipment and technology of the Paul Wurth company-a way of lowering the production cost of pig iron. Metallurgist 53(7-8):451-459 
Więcek M, Mróz J (2014) Characteristics of fine-grid iron-bearing materials-dusts, sludges, mill-scale sludges. Acta Metall Slovaca Conf 4:106-113

Winfield D, Cross M, Croft N, Paddison D (2012) Geometry optimisation of a gravity dust-catcher using computational fluid dynamics simulation. Chem Eng Process 62:137-144

Winfield D, Paddison D, Cross M, Croft N, Craig I (2013) Performance comparison of a blast furnace gravity dust-catcher vs. tangential triple inlet gas separation cyclone using computational fluid dynamics. Sep Purif Technol 115:205-215

Zhang F-M (2009) Study on dry type bag filter cleaning technology of BF gas at large blast furnace. In: Proceedings of the 5th international congress on the science and technology of ironmaking (ICSTI'09). The Chinese Society for Metals, Shanghai, pp 608-612 